\title{
Gestión de política pública para la celeridad en los procesos de pensión de alimentos en el Poder Judicial del Perú
}

\author{
Management of public policy for celerity up child support proceedings in the \\ peruvian judiciary
}

\section{Línea de Investigación: Sistemas Administrativos del Estado}

Recibido: 08 de mayo 2021

Aprobado: 16 de junio 2021

\section{RESUMEN:}

\section{AUTOR}

Mg. $\quad$ Fernández

Espinoza, William Homer

Magíster en Gestión Pública, Universidad de San Martín de Porres, Perú. Máster en Derecho de Familia e Infancia. Universitat de Barcelona: Barcelona, Catalunya, España.

ORCID:

https://orcid.org/00000003-4296-0467

Correo: william fernandez@usmp .pe
La presente investigación tiene como objetivo comprobar si mediante la gestión de política pública se logrará cumplir oportunamente los procesos de pensión de alimentos en los juzgados de paz letrado de los distritos judiciales del país. Para su desarrollo, se analizó la doctrina y se realizó un trabajo de campo a través de encuestas dirigidas a juezas y jueces de los juzgados de paz letrado de la Corte Superior de Justicia de Lima Norte, debido a las buenas prácticas que viene realizando este distrito judicial y porque obtuvo la certificación ISO 9001:2015 por la implementación de un sistema de gestión de calidad en atención a los procesos de pensión de alimentos. En cuanto a la metodología de investigación, esta es descriptiva y correlacional; y el método aplicado es el inductivo y los enfoques cuantitativo y cualitativo.

Del estudio de los resultados obtenidos se concluye que existe un sistema de gestión de procesos para la celeridad de las demandas de pensión de alimentos, establecido en los objetivos del Plan Nacional de Acceso a la Justicia de Personas en Condición de Vulnerabilidad 2016-2021, pero que este no se cumple, debido a diversos factores relacionados a la insuficiencia de recursos económicos, tecnológicos, materiales y humanos en el Poder Judicial del Perú.

Palabras clave: Celeridad; derechos humanos; economía; justicia.

\section{ABSTRACT:}

The objective of this research is to verify if through the management of public policy it will be possible to comply in a timely manner with the processes of child support in the courts of peace of the judicial districts of the country.

For its development, the doctrine was analyzed and field work was conducted through surveys directed to judges of the courts of peace of the Superior Court of Justice of North Lima, due to the good practices that this judicial district has been carrying out and because it obtained the ISO 9001:2015 certification for the implementation of a quality management system in attention to the processes of child support.

Regarding the research methodology, this is descriptive and correlational; and the method applied is the inductive and quantitative and qualitative approaches.

From the study of the results obtained, it is concluded that there is a process management system for the celerity of processes of child support claims, established in the objectives of the National Plan for Access to Justice for Persons in Condition of Vulnerability 2016-2021, but it is not met, due to various factors related to the insufficiency of economic, technological, material and human resources in the peruvian judiciary.

Keywords: Celerity; human rights; economy; justice. 


\section{INTRODUCCIÓN}

En la investigación se observó un problema acerca del tiempo de demora para la resolución de los procesos de pensión de alimentos en beneficio de las niñas, niños y adolescentes, debido, principalmente, al número insuficiente de juezas y de jueces de paz letrado que conocen de esta materia en todo el país. Además, por la gran carga procesal que tienen estos juzgados; la falta de personal de apoyo jurisdiccional y administrativo; y la ausencia de recursos materiales y tecnológicos que impiden que se resuelvan con celeridad estos casos.

Al respecto, debemos señalar que, desde el año 2016, el Consejo Ejecutivo del Poder Judicial aprobó el Plan Nacional de Acceso a la Justicia de Personas en Condición de Vulnerabilidad 2016-2021, mediante la Resolución Administrativa N090-2016-CE-PJ, el cual es el principal instrumento de gestión de este Poder del Estado, que promueve, en su primer eje poblacional, el efectivo acceso a la justicia para las niñas, niños y adolescentes. Asimismo, se establece como uno de sus objetivos, el lograr la celeridad en los procesos de pensión de alimentos.

Aunque, han sido diversas las acciones que se han realizado en los distritos judiciales en el Perú, que son 35 en total, es la Corte Superior de Justicia de Lima Norte la que ha destacado, debido a que, en marzo de 2018, obtuvo la certificación ISO 9001:2015 por la implementación de un sistema de gestión de calidad en atención a los procesos de pensión de alimentos en el Sexto Juzgado de Paz Letrado de Comas.

En tal sentido, en esta investigación, se estudiará las dificultades relacionadas a la falta de agilidad en la solución de los procesos de pensión de alimentos, teniendo como referente la experiencia del distrito judicial de Lima Norte, el cual está aplicando esta buena práctica y, en lo posible, promoveremos su réplica en los demás juzgados de paz letrado de la nación, lo que permitirá que estos juicios se resuelvan en el menor de los tiempos en beneficio de los usuarios judiciales.

Respecto a la metodología de investigación, esta es básica, no experimental y descriptiva, debido a que se analizaron las características importantes del problema estudiado, se formularon conclusiones y se propusieron recomendaciones. Además, el método utilizado es de carácter mixto: cuantitativo y cualitativo. Es cuantitativo, porque se utilizó el método hipotético, también se analizaron datos estadísticos en relevancia a los elementos del fenómeno investigado. $Y$ es cualitativo, porque se desarrolló la descripción de las cualidades del fenómeno, en base a datos históricos y bibliográficos.

\section{DESCRIPCIÓN DE LA SITUACIÓN PROBLEMÁTICA}

\subsection{Número de procesos judiciales}

Durante el período de enero a diciembre de 2018, ingresaron al Poder Judicial un total de 1'507,204 expedientes de distintas materias. Asimismo, fueron resueltos, ese año, 1'614,510 casos, de acuerdo al Boletín Estadístico Institucional N04-2018. De igual modo, durante el período de enero a diciembre de 2019, ingresaron al Poder Judicial un total de 1'605,728 expedientes. Asimismo, fueron resueltos 1'701,921 de casos, conforme al Boletín Estadístico Institucional N04-2019. En tal sentido, estas cifras evidencian un incremento considerable de expedientes que ingresan al sistema judicial, al comparar solo estos dos últimos períodos. También, que, el número de causas resueltas es similar a la cantidad de expedientes ingresados cada año y de aquellos en trámite que continúan desde el año anterior. Todo esto genera una sobrecarga procesal para los magistrados, quienes tienen la obligación constitucional de darles el trámite correspondiente.

\subsection{Cantidad de juezas y jueces}

En el 2018, el Poder Judicial tuvo un total de 3,215 juezas y jueces, entre supremos, superiores, especializados, mixtos y de paz letrado, así como 27,949 trabajadores 
administrativos y jurisdiccionales, de los cuales 17,887 laboraban bajo el régimen №728; así 6,708 por Contratación Administrativa de Servicios (CAS) a través de Decreto Legislativo $\mathrm{N}^{\circ} 1057$; y 3,354 bajo el régimen $\mathrm{N}^{\circ} 276$, de acuerdo a lo indicado en Boletín Estadístico Institucional $N^{\circ}$ 04-2018. Por otro lado, en el 2019, el número de juezas y jueces se elevó a 3,314. Asimismo, el número de trabajadores administrativos y jurisdiccionales también aumentó a 30,044 de los cuales 18,026 están bajo el régimen №728; así como 8,713 por el régimen CAS; y 3,305 en el régimen $\mathrm{N}^{\circ} 276$, conforme al Boletín Estadístico Institucional N04-2019. Como se observa, hubo un incremento de la cantidad de juezas y jueces a nivel nacional, pero muchos de ellos, quienes ocupan estos nuevos cargos, no son titulares sino que desempeñan estas funciones de forma provisional o por suplencia, debido a que, desde el 2018, se desactivó el Consejo Nacional de la Magistratura (CNM), el cual era el órgano encargado de nombrar, ratificar y destituir a los magistrados, y que, actualmente, es la Junta Nacional de Justicia (JNJ), conforme a la Ley №30916, la encargada de cumplir con aquellas labores, pero que aún no entra en funcionamiento para llevar a cabo los concursos públicos de méritos.

También, se evidencia un aumento de los puestos para trabajadores administrativos y jurisdiccionales, pero bajo el cuestionado régimen CAS y en menor medida en el régimen $\mathrm{N}^{\circ} 728$. Por el contrario, los puestos de trabajo en el régimen $\mathrm{N}^{\circ} 276$, es decir por contrato indeterminado, han disminuido.

Sin embargo, en marzo de 2021 se promulgó la Ley №31131 que establece disposiciones para erradicar la discriminación en los regímenes laborales del sector público, el cual tiene por objetivo incorporar al régimen laboral del Decreto Legislativo $\mathrm{N}^{\circ} 728$, a los trabajadores que desarrollan labores permanentes en las diversas entidades del Estado, contratados bajo el Decreto Legislativo №1057 que regula el régimen CAS. Esperamos que las deficiencias antes mencionadas puedan superarse con la entrada en vigor de esta nueva norma, pero se debe resaltar que ello sería ineficaz sin las disposiciones de las partidas presupuestales respectivas.

\subsection{Carga procesal por juzgado}

El Poder Judicial, a través de las 35 Cortes Superiores de Justicia, cuenta con 638 juzgados de paz letrado de los cuales son titulares 138 juezas y 151 jueces, es provisional 1 juez, y son suplementes 200 juezas y 148 jueces (Comisión de Justicia de Género, 2018).

Son los juzgados de paz letrados los órganos jurisdiccionales competentes para resolver los procesos de pensión de alimentos en primera instancia. En el 2018, se calculó la existencia de un total de 211,964 de estos expedientes a nivel nacional, de los cuales 114,787 ingresaron ese año; 91,524 estaban en trámite; y 5,653 fueron archivados, de acuerdo a la Base de datos de expedientes del Sistema Integrado Estadístico de la Central de la Gerencia General del Poder Judicial.

En ese sentido, también en el 2018, calculando el número de 638 juezas y jueces de paz letrados y el de 211,964 causas judiciales, aunque la carga no está distribuida de manera uniforme, debido a que en algunos distritos jurisdiccionales se cuenta con una mayor o menor cantidad de estos juzgados, la carga procesal puede mantener un promedio de 1,000 casos de pensión de alimentos por juzgado, y, adicionalmente, los otros expedientes de su competencia, generando que un juzgado llegue a contar con un promedio de 3,000 expedientes bajo su cargo al año.

Por otro lado, la carga de procesos de alimentos, aunque disminuyó en el 2019, se sigue manteniendo alta, llegando a los 195,571 casos. Asimismo, la cantidad de ingresos y de causas en trámite es grande, con 101,249 y 88,765 expedientes, respectivamente, según la Base de datos de expedientes del Sistema Integrado Estadístico.

\subsection{Políticas del Poder Judicial del Perú}

El 7 de abril de 2016, el Consejo Ejecutivo del Poder Judicial promulgó el Plan Nacional de Acceso a la Justicia de Personas en Condición de Vulnerabilidad 20162021, para la eficacia de las "Reglas de Brasilia" aprobadas por la Cumbre Judicial 
Iberoamericana en Brasil, en el 2008, a las cuales este Poder del Estado se adhirió a través de la Resolución Administrativa N²66-2010-CE-PJ, así como a la actualización de su texto, llevada a cabo en Ecuador, en el 2018, por las Resoluciones Administrativas $\mathrm{N}^{\circ}$ 002-2020-CE-PJ y Nº00198-2020-CE-PJ, disponiendo su aplicación en todos los órganos jurisdiccionales y administrativos, a nivel nacional.

El Eje N¹: "Niñas, Niños y Adolescentes" del referido plan nacional, tiene como objetivo estratégico aplicar la justicia itinerante y promover la celeridad en los procesos de pensión de alimentos. Para ello, el Consejo Ejecutivo del Poder Judicial aprobó el "Protocolo de Justicia Itinerante para el Acceso a la Justicia de Personas en Condición de Vulnerabilidad", mediante la Resolución Administrativa N²64-2017-CE-PJ, que es el instrumento que regula este servicio judicial que brindan los juzgados de paz letrado que se trasladan a aquellos lugares de escasos recursos económicos o en situación de pobreza, que concentran a grupos vulnerables, acercando la justicia en materia de alimentos. Además, a través de la Resolución Administrativa №331-2018-CE-PJ, se aprobó la actualización del formulario de demanda de alimentos para niñas, niños y adolescentes. Y, recientemente, se autorizó la directiva del proceso simplificado y virtual del proceso de alimentos, por la Resolución Administrativa º167-2020-CE-PJ.

De igual forma, el Poder Judicial cumplió con el Plan de Gestión y Desarrollo para el período 2019-2020, especialmente, para la mejora de la atención al usuario judicial. Asimismo, con la vigencia de la Política Nacional de Modernización de la Gestión Pública al 2021, se generó la aprobación del Expediente Judicial Electrónico (EJE) y su respectivo reglamento, a través de la Resolución Administrativa º228-2017-CE-PJ, con el objetivo de fijar las reglas relativas a la formación, trámite, ejecución y archivo del expediente digital para todos los órganos jurisdiccionales.

Todo lo anterior, guarda concordancia con lo dispuesto en los artículos 3, 8, 12 y 27 de la Convención sobre los Derechos del Niño, de acuerdo a la doctrina de la protección integral. Así como, a lo establecido en las observaciones generales del Comité de los Derechos del Niño del cual el Estado peruano forma parte y ha asumido responsabilidades internacionales para garantizar la protección de los derechos fundamentales.

Además, esta política del Poder Judicial está acorde a lo indicado en los artículos 4 , 138 y 139 de la Constitución Política; de lo señalado en la Ley N³0466 que establece garantías y parámetros procesales para la consideración fundamental del interés superior del niño y su respectivo reglamento, aprobado por el Decreto Supremo N0022018-MIMP; de lo dispuesto en los artículos 6, 92 y 93 del Código de los Niños y Adolescentes; de los artículos 19, 20, 402, 413, 472 y 481 del Código Civil; y de los artículos 85, 424, 425 y siguientes del Código Procesal Civil, entre otras leyes especiales sobre la materia.

Del mismo modo, se cumple con la política del Estado peruano contenida en el "Plan Nacional de Acción por la Infancia y la Adolescencia 2012-2021", aprobado por el Decreto Supremo N001-2012-MIMP y elevado mediante la Ley $\mathrm{N}^{\circ} 30362$, el cual tiene como objetivo lograr la protección de los derechos de las niñas, niños y adolescentes, especialmente su derecho a los alimentos.

\subsection{Buenas prácticas de la Corte Superior de Justicia de Lima Norte}

La Corte Superior de Justicia de Lima Norte, a través de la Resolución Administrativa №142-2017-P-CSJLN/PJ, del 1 de febrero de 2017, conformó la comisión de trabajo integrada por juezas y jueces dentro del marco de "Celeridad en los procesos de alimentos en los juzgados de paz letrado". Designando al Sexto Juzgado de Paz Letrado del distrito de Comas para la implementación del proyecto piloto para la Certificación ISO 9001:2015, mediante la Resolución Administrativa N³91-2017-P-CSJLN/PJ, del 17 de abril de ese mismo año.

El 1 de junio de 2017, por la Resolución Administrativa N559-A-2017-P-CSJLN/PJ, se aprobó la Política de Calidad de la Corte Superior de Justicia de Lima Norte. Y, por la Resolución Administrativa N600-2017-P-CSJLN/PJ, del 12 de junio, se estableció el marco de los documentos de gestión que norman los procesos de personal y estructura 
de cargos, puestos y funciones que ostentan los trabajadores que están involucrados en el proceso de implementación del Sistema de Gestión de Calidad, a través de la certificación de cumplimiento de la Norma ISO 9001:2015.

El 28 de febrero de 2018, por la Resolución Administrativa N¹88-2018-P-CSJLN/PJ, se dispone que se inicien las acciones administrativas correspondientes para la implementación de la Norma ISO 9001:2015, a partir del mes de marzo de ese año. Es así que, se implementó el Sistema de Gestión de Conclusión Célere de Procesos de Pensión de Alimentos en los juzgados de paz letrado, de acuerdo a la Resolución Administrativa $\mathrm{N}^{\circ} 246-2018-\mathrm{P}-\mathrm{CSJLN} / \mathrm{PJ}$, del 20 de marzo.

De igual forma, por la Resolución Administrativa N421-2018-P-CSJLN/PJ, del 9 de mayo de 2018, se aprobó la implementación del Sistema de Gestión para el Aceleramiento de los Procesos de Familia a cargo de los juzgados especializados y mixtos, quienes tienen competencia en los procesos de pensión de alimentos como órganos jurisdiccionales de segunda instancia, cuando la relación paterna/materno filial ha sido determinada.

En tal sentido, el distrito judicial de Lima Norte estableció un novedoso sistema de gestión para la agilidad en los procesos de pensión de alimentos en los juzgados de paz letrado de su jurisdicción. En el 2018, según la Base de datos de expedientes del Sistema Integrado Estadístico del Poder Judicial, el reporte de procesos en materia de alimentos en estos juzgados era de 11,784 expedientes, de los cuales 6,632 ingresaron ese año; 5,052 estaban en trámite y se archivaron 100 causas.

Durante el proceso de implementación y aplicación de la Norma ISO 9001:2015, para la conclusión célere en los procesos de alimentos, se evidenció que, en el 2019, de acuerdo a la Base de datos de expedientes del Sistema Integrado Estadístico, el reporte de procesos en materia de alimentos en los juzgados disminuyó considerablemente a 10,109 expedientes, de los cuales 5,874 ingresaron; 4,179 estaban en trámite; y solo se archivaron 56.

Por tal motivo, consideramos que el distrito judicial de Lima Norte es un modelo a seguir por los demás distritos judiciales, especialmente, en aquellos que mantienen una gran carga procesal y pocos juzgados que asuman esa labor, para lograr una mejor distribución de los expedientes, la celeridad para resolver dentro del plazo legal las causas, y aplicando, además, el principio de economía procesal a favor de las partes involucradas y, también, para el tesoro público.

\section{BASES TEÓRICAS}

\subsection{La protección integral de la niña, niño y adolescente}

A partir de la adopción de la Convención sobre los Derechos del Niño (1989) por las Naciones Unidas, se implementó el paradigma de la protección integral, que es concordante con los tratados e instrumentos de protección de los derechos humanos en favor de la infancia.

Esta doctrina reconoció a la niña, niño y adolescente como sujetos plenos de derechos y ya no como objetos de protección, como se había establecido anteriormente. Con este nuevo paradigma, se transformó la concepción que se tuvo de los menores de edad, al dejar de considerarlos como incapaces (Beloff; 2001; p.301).

En ese sentido, la aprobación de la convención fue sumamente importante al reconocer a los niños como personas, tal como habrían sido considerados, también, en otros instrumentos internacionales como la Declaración de los Derechos del Niño (1959), estableciéndose así, los estándares para garantizar su defensa y reconocer su autonomía e interés superior (O’Donnell; 2001; p.23).

\subsection{El derecho fundamental a la pensión de alimentos}

La Constitución Política señala, en su artículo 4, que el Estado protege a la niña, niño y adolescente, particularmente, cuando se halla en situación de vulnerabilidad, para garantizar el ejercicio pleno de todos sus derechos reconocidos en los tratados e 
instrumentos internacionales, en defensa de su integridad, durante este tiempo de desarrollo y evolución en que se encuentran, para que lleguen de la mejor manera a la adultez. La protección de la persona se funda en su dignidad, como fin supremo, por el que el Estado debe estar al servicio de la defensa para su bienestar (Landa; 2017; p.17).

En ese sentido, esta Convención que ha sido ratificada mediante la Resolución Legislativa $N^{\circ} 25278$ del 3 de agosto de 1990, y cuyo contenido forma parte de la normativa nacional, señala en sus artículos 24 y 27, que la niña, niño y adolescente tiene el derecho a un nivel adecuado de vida para su desarrollo holístico, por lo que es responsabilidad primordial de sus progenitores el proporcionarles, dentro de sus posibilidades, lo esencial para su alimentación, nutrición, vestuario, vivienda, educación, entre otros que requiera para su formación integral. Esta disposición tiene su antecedente en el artículo 11 del Pacto Internacional de Derechos Económicos, Sociales y Culturales (1976) y en el artículo 4 de la Declaración de los Derechos del Niño.

Por su parte, los artículos 92 y 93 del Código de los Niños y Adolescentes guardan completa concordancia con este concepto, el cual, también, ha sido explicado, ampliamente, en la Observación General $N^{\circ} 15$ del Comité de los Derechos del Niño (2013) sobre el disfrute del más alto nivel de salud de los menores de edad, en el que está comprendido el derecho humano a la alimentación.

No obstante, la Defensoría del Pueblo (2018; p.180) a través de sus informes temáticos concluyó que, en el Poder Judicial, existe una excesiva demora en el desarrollo del proceso de pensión de alimentos, generando una situación de indefensión y vulnerabilidad para la parte demandante y en especial para la persona que requiere alimentos, que en su mayoría son niñas, niños y adolescentes. Asimismo, que estos juicios tardan hasta medio año para que se emita una sentencia, cuando la vía procedimental para su trámite es el proceso único, similar al sumarísimo, pero con plazos más cortos. Además, que, se presenta un retraso en su ejecución, debido a que la mayoría de las pensiones son cumplidas en un lapso de hasta 15 meses. También, se observó que, el número de juezas y jueces de paz letrado no son suficientes para atender al gran número de expedientes de pensión de alimentos que ingresan cada año, y que, son pocos los magistrados que se capacitan constantemente sobre la materia, especialmente aquellos que trabajan en lugares geográficamente alejados y que tampoco pueden comunicarse directamente con las partes por el desconocimiento de las lenguas originarias de la zona, no siendo posible contar con un intérprete por la falta de éstos en aquellos distritos judiciales, generando barreras, además de económicas, de carácter social y cultural.

\subsection{Política pública de acción a favor de la infancia y la adolescencia}

En el 2012, se promulgó el Plan Nacional de Acción por la Infancia y la Adolescencia 2012-2021, para continuar con la implementación y el fortalecimiento de las disposiciones establecidas por la Convención y, en particular, de las políticas públicas para efectivizar el derecho a la alimentación de las niñas, niños y adolescentes.

Años más tarde, en el 2016, se aprobó el Plan Nacional de Acceso a la Justicia de Personas en Condición de Vulnerabilidad 2016-2021, para la eficacia de las Reglas de Brasilia, en las cuales se reconoce que la niña, niño y adolescente se encuentra en condición vulnerable por su motivo de su edad, sumado a otras causas que podrían agravarla como el género, la discapacidad, la proveniencia de pueblos originarios, ser víctima de discriminación y/o de violencia, entre otras, de acuerdo a lo sostenido en las Reglas de Brasilia 3 y 5, cuando encuentren especiales dificultades para ejercitar sus derechos ante el sistema de justicia. Como ocurre, actualmente, con el proceso de pensión de alimentos y los obstáculos que impiden su célere desarrollo.

Además, esta posición es asumida en la Agenda 2030 para los Objetivos del Desarrollo Sostenible (Naciones Unidas, 2015), en el objetivo 16.10, para garantizar el acceso a la justicia y el ejercicio de las libertades fundamentales de la persona, especialmente, para aquellas que se enfrentan a múltiples barreras por circunstancias económicas, políticas, sociales y culturales. 
Por tal motivo, el concepto de política pública está vinculada a erradicar las desigualdades sociales, políticas y económicas dirigidas a favor de las personas vulnerables. Entonces, su gestión es encargada a la autoridad pública (Velásquez; 2009; p.156). También, es entendida como las acciones que desarrolla el Estado para satisfacer las necesidades ciudadanas (Boneti; 2017 ; p.13). Y, está orientada a la obtención de resultados medibles, los cuales serán monitoreados para su evaluación y mejoramiento, para ser replicada en otros sectores (Lahera; 2006; p.77).

Cuando hablamos de la gestión de política pública vinculada a la justicia, se orienta a garantizar su acceso, la atención célere y pronta solución del conflicto, evitando retrasos injustificados y optimizando los componentes humanos y materiales del servicio.

\subsection{El proceso de pensión de alimentos}

El derecho de alimentos es fundamental para el menor de edad, el cual comprende la alimentación, educación, vestido, medicina y recreación, contabilizado desde que la madre está embarazada hasta después del parto. Cuando no es cumplido este derecho, puede demandarse ante el juez de paz letrado, quien determina la cuantía, de acuerdo a la edad y requerimientos del niño, siempre que se acredite el vínculo familiar. El juicio se desarrolla bajo la vía del proceso único (artículos 92, 170 y 173 del Código de los Niños y Adolescentes).

En el 2004, se publicó la Ley №28439 que simplificó las reglas del proceso de pensión de alimentos, modificando el artículo 57 de la Ley Orgánica del Poder Judicial y el artículo 96 del Código de los Niños y Adolescentes, para establecer su competencia a los juzgados de paz letrado, justamente porque éstos están instalados en aquellos lugares que concentran a las poblaciones vulnerables. Asimismo, se modificó el artículo 424 del Código Procesal Civil, disponiéndose que no era exigible la firma del abogado para la presentación de la demanda, flexibilizando el proceso y promoviendo su gratuidad. Además, el Poder Judicial aprobó y fomentó el uso de un formulario accesible digitalmente y de fácil llenado, por la Resolución Administrativa №51-2005-CE-PJ.

El acceso a la justicia es fundamental para la defensa de los derechos, pero no basta con presentar un reclamo o la demanda, sino que esta se siga mediante una debida y diligente tutela jurisdiccional, lo cual formará parte para el ejercicio de todos los demás derechos fundamentales relacionados al proceso (Priori; 2019; p.82). No obstante, también es importante el acercamiento de estos servicios a la comunidad.

Por ese motivo, en el 2017, el Poder Judicial institucionalizó el servicio de justicia itinerante, el cual se define como el traslado de los operadores de justicia a aquellos lugares en situación de pobreza o pobreza extrema, urbano marginales, que se encuentren en zonas geográficamente lejanas o con dificultades especiales de comunicación, para el acercamiento de los servicios judiciales a las comunidades menos favorecidas, de acuerdo a lo señalado en el artículo 6.1.2. del protocolo de justicia itinerante, en concordancia con la Regla de Brasilia 42, sobre la proximidad de la justicia a la sociedad.

Dentro de este servicio se encuentra el proceso de pensión de alimentos, y para integrarlo, en ese mismo año, el Consejo Ejecutivo del Poder Judicial aprobó la actualización el formato de demanda de pensión de alimentos, mediante la Resolución Administrativa $\mathrm{N}^{\circ} 331-2018-\mathrm{CE}-\mathrm{PJ}$, pero esta vez sería un formulario exclusivo para demandas a favor de los menores de edad. Así como, por la Resolución Administrativa N³30-2018-CE-PJ, se aprobaría el formulario de demanda de aumento de pensión de alimentos, y, por la Resolución Administrativa N³32-2018-CE-PJ, se extendió la materia del formato para la acumulación de la demanda de filiación judicial de paternidad extramatrimonial y de pensión de alimentos para niñas, niños y adolescentes.

Estas acciones que ha venido realizando el Poder Judicial tienen como finalidad garantizar el acceso a la justicia y otorgar una mayor celeridad a los procesos de pensión de alimentos frente a los problemas existentes, que no permiten reducir la carga procesal en los juzgados de paz letrado. Además de involucrar a la población que no puede demandar por su lejanía o la falta de conocimiento sobre estos mecanismos, para 
la protección de sus derechos fundamentales y que tengan mayor accesibilidad a estos servicios, es especial para solicitar la pensión de alimentos para el niño, ante el incumplimiento de las obligaciones parentales por uno de sus progenitores.

\subsection{El proceso simplificado y virtual de pensión de alimentos}

El Consejo Ejecutivo del Poder Judicial, mediante la Resolución Administrativa №167-2020-CE-PJ del 4 de junio de 2020, aprobó la Directiva N007-2020-CE-PJ que regula el proceso simplificado y virtual de pensión de alimentos para niños.

El proceso de simplificación y virtualización del proceso comenzó en febrero de 2020 , con la aprobación del formulario electrónico para el ingreso virtual de demandas en esta materia, mediante la Resolución Administrativa N082-2020-CE-PJ, al digitalizar los formatos que se utilizaban en el servicio de justicia itinerante, a fin de que sean llenados, firmados y enviados a las mesas de partes electrónicas habilitadas por las Cortes Superiores de Justicia, generando que no sea necesario que se concurra personalmente ante las instalaciones de los tribunales.

En ese sentido, en junio de ese año, debido a la pandemia del COVID-19, se aprobó este proceso virtualizado, en base a diversos principios que han sido flexibilizados por la Corte Suprema de Justicia, de acuerdo al contenido del Tercer Pleno Casatorio, recaído en la Casación N4664-2010-Puno, sobre la función tuitiva que debe cumplir la jueza o el juez en los procesos de familia para solucionar con prontitud los conflictos que surgen dentro de esta esfera y entre sus integrantes (2010; p.19).

En la referida directiva se destaca la aplicación del principio del interés superior de la niña, niño y adolescente, a través de la obligación de garantizar el derecho alimentario para su desarrollo integral. Seguido por el principio "favor minoris" que, en caso de dudas respecto a las posibilidades económicas del obligado, la interpretación de la ley y sobre el caso debe ser en beneficio del alimentista. Asimismo, se aplican los principios de celeridad y la percepción del tiempo, los cuales señalan que, debe darse prioridad en la atención del proceso y resolverse en el menor de los plazos posibles, pero dentro de la legalidad, al igual que la ejecución de la sentencia para el cumplimiento de la pensión alimentaria.

Por tal motivo, entrando al desarrollo del proceso en sí, en la etapa postulatoria, para la presentación de la demanda, se utilizará el formato electrónico que será ingresado y registrado en el Sistema Integrado Judicial, a través de la mesa de partes virtual, en el que se consignará un código de digitalización de recepción del documento enviado.

Para la calificación de la demanda, se aplican las reglas establecidas en el artículo 165 del Código de los Niños y Adolescentes, en concordancia con los artículos 426 y 427 del Código Procesal Civil. Lo resaltante en esta directiva es que, cuando el magistrado advierta la omisión o un defecto subsanable, no declarará la inadmisibilidad, sino la admisión a trámite, concediendo a la parte demandante un plazo razonable, para subsanarlo, evitando que innecesariamente se suspenda.

Verificados los requisitos de procedencia, así como el control de admisibilidad de los medios probatorios ofrecidos, la jueza o el juez emite el auto admisorio de la causa, señalando, conjuntamente, la fecha para la realización de la audiencia única de forma virtual, dentro de los próximos 10 días, de acuerdo a lo señalado en el artículo 170 del Código de los Niños y Adolescentes, y se dispondrá, de oficio, la medida cautelar de asignación anticipada de alimentos. También, puede ordenar que se oficie al empleador del demandado, si lo tuviere, a fin de que éste remita información sobre la situación laboral y la capacidad económica del obligado y cumpla con el descuento respectivo del pago en planilla, aplicando el principio de concentración procesal.

La notificación del auto admisorio se envía a la casilla electrónica de las partes, a través del Sistema de Notificaciones Electrónicas (SINOE) del Poder Judicial, y, excepcionalmente, a los correos electrónicos y por comunicación a las aplicaciones para teléfonos móviles, tales como "whatsapp" u otros similares.

Para la contestación de la demanda, el plazo es de 5 días, de acuerdo al artículo 168 del Código de los Niños y Adolescentes. Sin embargo, ésta no se dará por admitida cuando el demandado no cumpla con presentar la declaración jurada de renta, 
documento sustitutorio o certificación jurada de ingresos, bajo apercibimiento de que se declare su rebeldía en el proceso.

La audiencia única es dirigida por la jueza o el juez, que se realiza de manera virtual y bajo el sistema de la oralidad, la cual será grabada para su registro en audio y video, a excepción de la etapa de conciliación, a través de la herramienta digital de "Google Hangout Meet" u otro medio apto para llevar a cabo videollamadas, videoconferencias o similares, para garantizar la conservación y reproducción de su contenido, que será incorporada al expediente y registrada en el Sistema Integrado Judicial, guardando la confidencialidad y la reserva de los datos de las partes del proceso. Ello se realiza en cumplimiento de los principios de inmediación, oralidad y de interés superior del niño, flexibilizando lo dispuesto en los artículos 171 y 173 del Código de los Niños y Adolescentes, los cuales disponen que, tradicionalmente, la audiencia se realice de forma presencial para la acreditación de las partes y los abogados, y la interacción directa con el magistrado. Además, que el desarrollo de las actuaciones judiciales quedaba plasmado en un acta en papel, cuando, ahora, se dejará constancia a través del vídeo y la validación de las firmas digitales acreditadas ante el RENIEC.

En esta audiencia virtual se concentran las etapas de saneamiento procesal y de conciliación, de ser el caso, pero si no se logra que lleguen a acuerdos satisfactorios para el menor de edad, el magistrado continúa con la fijación de los puntos controvertidos, la admisión de los medios probatorios, así como incorporar nuevos medios de prueba que serán oralizados, previo traslado a la otra parte, y la actuación de las mismas, cumpliéndose así con el principio de amplitud probatoria. De igual manera, la jueza o el juez promueve el debate oral entre las partes procesales, los alegatos de los abogados y dirige todas las actuaciones hasta la emisión de la sentencia.

Un punto muy importante que ha sido incorporado en esta directiva, es garantizar la participación de la niña, niño y adolescente en el proceso judicial, que, de acuerdo a su edad y madurez, será informado a través de un lenguaje claro, sencillo y en su idioma materno sobre la finalidad del juicio y sus consecuencias, para que sea escuchado y se tome en cuenta su opinión en la decisión final.

Cuando no concurra el demandado a la audiencia, aunque haya sido válidamente notificado, el magistrado procederá a emitir la sentencia, en el mismo acto, atendiendo a las pruebas actuadas. De otro lado, cuando no se presenten ninguna de las partes y existan todos los medios de prueba, cumpliendo con el principio de flexibilización y de la función tuitiva de la jueza o el juez, éste resolverá sin la presencia de las partes, en aplicación primordial del principio del interés superior del niño.

Terminada la audiencia, inmediatamente, el magistrado dictará sentencia de forma oral, que será leía en su integridad o solo la parte resolutiva, de acuerdo a la carga procesal o la complejidad del caso. Asimismo, ésta será notificada a la casilla electrónica respectiva de las partes, y, de igual manera, se remitirá la grabación de la audiencia en soporte electrónico.

\section{ANÁLISIS Y DISCUSIÓN DE RESULTADOS}

Para el desarrollo del trabajo de investigación, se encuestó a la muestra censal de doce (12) juezas y jueces de los juzgados de paz letrado del distrito judicial de Lima Norte (aprobado y realizado a través de la Resolución Administrativa №00007-2020OAL-P-CSJLIMANORTE-PJ del 17 de enero de 2020), con el objetivo de comprobar si mediante la gestión de política pública se logrará cumplir oportunamente los procesos de pensión de alimentos. Además, de demostrar cómo los juzgados de paz letrado que no tratan con celeridad los procesos de pensión de alimentos perjudican a la parte demandante; y determinar por qué no se cumple el sistema de gestión de procesos para garantizar la celeridad de las demandas de pensión de alimentos en el Poder Judicial, pese a que ésta es una política institucional aprobada.

En ese sentido, la propuesta de valor se relaciona a la gestión de política pública para la promoción de la cultura jurídica hacia la población en materia de alimentos; para la protección de los grupos vulnerables que demandan alimentos; para disminuir la carga 
procesal en materia de pensión de alimentos; para la celeridad en los procesos de pensión de alimentos; y para la implementación de recursos materiales, herramientas tecnológicas y personal en los juzgados de paz letrado.

\subsection{Promoción de la cultura jurídica ciudadana en materia de alimentos}

Se preguntó ¿consideran que los usuarios cuentan con información accesible y completa sobre el proceso de alimentos? La mayoría contestó que no (58\%), pese a que la información relacionada a este tema es difundida masivamente a los ciudadanos a través de las oficinas de atención de los usuarios en las instalaciones de la corte suprema y de las cortes superiores de justicia del país, además de la página web institucional y las redes sociales.

De igual forma, se preguntó ¿consideran que se promueve el uso de los formularios de demandas de alimentos? La mayoría respondió que no (75\%), aunque estos nuevos formularios han sido aprobados desde el 2018.

En tal sentido, se evidenció que, si bien existe información accesible a través de diversos canales de comunicación, ésta no llega a la población que realmente la requiere, especialmente para aquella en situación vulnerable por encontrarse en zonas alejadas, lugares de difícil acceso, comunicación y/o urbano marginales.

Estas actividades deben materializarse a través de una gestión de política pública para la promoción de la cultura jurídica en materia de alimentos, planificando la realización de ferias de fomento de derechos ciudadanos de manera itinerante y permanente en coordinación intra e interinstitucional con los diversos sectores del Estado, especialmente por parte del Poder Judicial.

\subsection{Protección de los grupos vulnerables que demandan alimentos}

Se preguntó ¿consideran que la mayoría de las demandas de alimentos son solicitadas para menores de edad? Todos contestaron que si (100\%). Lo que demuestra que la población que accede a este servicio de tutela judicial es menor de edad, a través de la representación de sus progenitores (en su mayoría por las madres), tutores o representantes legales, para garantizar su derecho a la alimentación.

En tal sentido, debe establecerse una gestión de política pública para la protección de los grupos vulnerables que demandan alimentos. En especial, cuando consideramos que la gran mayoría de la población que asiste a los juzgados a presentar una demanda de alimentos no conocen sus propios derechos o los de sus hijas e hijos, ni los alcances de la obligación alimentaria, como lo sostiene Hilal Elver (2019) en su trabajo a través de UNICEF, para fortalecer los derechos humanos de los ciudadanos en situación de pobreza.

\subsection{Reducción de la carga procesal en materia de alimentos}

Se preguntó ¿la mayor carga procesal de sus juzgados son los casos de alimentos? La mayoría (83\%) contestó que sí. Esto demuestra que, la mayor labor de los magistrados es resolver procesos de alimentos, además de otras causas judiciales que son de su competencia, que también se advierte llegan a un número elevado de expedientes de manera mensual y anual, tal como lo sostiene la Defensoría del Pueblo (2018).

Hay que tener en consideración que, desde hace algunos años, la propuesta del Estado se enfocó en promover la conciliación extrajudicial. No obstante, en la práctica, se presenta un problema relacionado al incumplimiento de estas actas de conciliación que, al final, terminan siendo judicializadas para su ejecución efectiva, lo que también eleva la carga laboral en los juzgados.

Más aún, debemos observar que la mayoría de la población desconoce sus derechos en materia de alimentos, y muchos de ellos no demandan. A partir de la promoción de la cultura jurídica a los usuarios, aumentará la presentación de demandas, incluyendo las facilidades que se les dan a los justiciables, como la presentación de formularios de demandas de fácil llenado y de entrega gratuita, así como que, no se necesita la firma 
de abogado para su admisión y la defensa pública que brinda sin costos el Poder Ejecutivo, a través del Ministerio de Justicia y Derechos Humanos.

En tal sentido, se debe aprobar, a nivel nacional, una gestión de política pública para reducir la carga de procesos de alimentos, teniendo como ejemplo las buenas prácticas desarrollas en el distrito judicial de Lima Norte, a través de la implementación de la Norma ISO 9001:2015 y del Sistema de Gestión de Conclusión Célere de Procesos de Alimentos en los juzgados de paz letrado.

En consecuencia, quedó comprobado que, mediante la gestión de política pública por el Poder Judicial, se logrará cumplir oportunamente los procesos de pensión de alimentos en los juzgados de paz letrado, a nivel nacional.

\subsection{Promoción de la celeridad en los procesos de alimentos}

El proceso de alimentos, según la ley, debería tener una duración aproximada de 30 días hábiles. Al respecto, se preguntó ¿la calificación de la demanda se realiza realmente dentro del plazo legal? La mayoría de los encuestados contestó que sí (83\%).

Asimismo, se preguntó ¿se realiza de forma célere la notificación a las partes en el proceso de alimentos? La respuesta del $42 \%$ fue que no, lo cual es preocupante debido a que demuestra que cerca de la mitad de los juzgados tienen problemas relacionados a la notificación, especialmente a la parte demandada, debido a que no se ubica su residencia, el cambio de domicilio o porque viven al interior del país o en el extranjero, lo que puede retrasar hasta 6 meses el proceso de alimentos.

De igual forma, se preguntó ¿se programa con celeridad la audiencia? Nuevamente, el $42 \%$ de las juezas y jueces contestaron que no, debido al problema de la notificación y el aplazamiento de fechas, haciendo que el proceso demore más de lo necesario y se vulnere los derechos del alimentista.

En ese sentido, se preguntó ¿los procesos de alimentos son resueltos realmente dentro del plazo legal? La respuesta fue en su mayoría que no (67\%), lo que evidencia que, aunque la legislación establezca una seria de plazos para el desarrollo célere, prioritario y en el menor número de actos por parte del sistema de justicia (economía procesal), se presentan diversas circunstancias en la realidad que impiden su normal progreso y su conclusión en una posible sentencia favorable para el alimentista menor de edad, quien además de encontrarse en una situación de necesidad, sufre múltiples causas de vulnerabilidad por su edad, género, condición económica, social y/o cultural.

Por otro lado, suponiendo que el proceso de alimentos culmine de forma rápida y en favor de la parte demandante, se presenta otro problema relacionado a la ejecución de la sentencia. La Defensoría del Pueblo (2018) había evidenciado ese problema, en la demora en el cumplimiento de la pensión de alimentos de hasta 15 meses (p.180).

Al respecto, se preguntó ¿la ejecución de la sentencia se desarrolla de forma célere? La mayoría (67\%) respondió que no. Esto demuestra que surge otra problemática respecto a la ejecución de la sentencia de alimentos, que impide el cobro de la pensión a favor de la niña, niño o adolescente, debido al desempleo del progenitor, la insuficiencia económica del demandado o simplemente porque se niega a pagar.

Aunque esta situación puede solucionarse a través de diversas medidas legales, como el embargo de bienes, la retención de dinero en cuentas bancarias u otras que estime la jueza o el juez en aplicación de la legislación correspondiente, como la denuncia por la comisión del delito a la omisión de la asistencia familiar, el problema surge en el plazo que transcurre, desde la demanda, la asignación anticipada de una pensión de alimentos, la emisión de la sentencia y la ejecución de la misma, lo que puede generar que estos duren, incluso, años.

En consecuencia, queda demostrado que los juzgados de paz letrado que no tratan con celeridad los procesos de pensión de alimentos, perjudican a la parte demandante, principalmente los derechos fundamentales de la niña, niño y adolescente alimentista.

Por tal motivo, se debe aprobar y llevar a cabo una gestión de política pública para la celeridad en los procesos de alimentos, incluyendo el uso de las nuevas tecnologías, tales como el Expediente Judicial Electrónico para los juzgados de paz letrado, la notificación virtual, incluso aquella realizada por edictos a través del portal institucional, 
la programación de la audiencia única que debe ser fijada en la misma resolución que admite a trámite la demanda, del mismo modo emitir la sentencia y su ejecución, dentro de un plazo razonable.

\subsection{Implementación de recursos materiales, tecnológicos y humanos}

En el trabajo de investigación se observaron otros problemas vinculados a la insuficiencia de recursos materiales, tecnológicos y humanos del Poder Judicial, que impiden que la gran carga de procesos de alimentos se atienda de forma prioritaria y se resuelvan de manera célere, como lo expone Hernán Gómez (2013) en su investigación con la CEPAL; es decir, se necesita una reforma de políticas judiciales que garanticen los derechos de la población.

Al respecto, se preguntó ¿consideran que los procesos de alimentos no se realizan con celeridad debido a la falta de un número mayor de juzgados? La respuesta en su mayoría fue que sí (92\%). Aunque, en la Corte Superior de Justicia de Lima Norte se observó una mejora en la disminución de la carga en materia de alimentos desde la implementación de la Norma ISO 9001:2015 y la aprobación del Sistema de Gestión de Conclusión Célere de Procesos de Alimentos en los juzgados de paz letrado, la realidad es distinta en diversos distritos judiciales del país.

Asimismo, se preguntó ¿consideran que los procesos de alimentos no se realizan con celeridad por la falta de personal jurisdiccional y administrativo? La mayoría contestó que si (92\%), lo que demuestra que, además de la falta de juezas y jueces para resolver las causas, es necesario el apoyo de personal que proyecte las resoluciones, acompañe al magistrado en el desarrollo de las actuaciones procesales y realice funciones administrativas, tales como las notificaciones, entre otras.

De mismo modo, se preguntó ¿consideran que los procesos de alimentos no se realizan con celeridad por la falta de recursos materiales y/o tecnológicos en los juzgados? La mayoría respondió que no (67\%) debido a que, dependiendo de las zonas donde se encuentran ubicados los órganos jurisdiccionales, así como su antigüedad, se presenta la falta de equipos muebles y computarizados, y el acceso a internet, para desarrollar el trabajo, lo que genera un retraso en el proceso judicial.

La Defensoría del Pueblo (2018) evidenció estas deficiencias y retos en el proceso de pensión de alimentos, a nivel nacional, desde hace mucho tiempo atrás. Por lo que queda demostrado que no se cumple el sistema de gestión de procesos para garantizar la celeridad de las demandas de pensión de alimentos en el Poder Judicial, pese a que, desde el abril de 2016, fue aprobado el Plan Nacional de Acceso a la Justicia de Personas en Condición de Vulnerabilidad al 2021.

En consecuencia, observamos que se requiere efectuar una gestión de política pública para la implementación de recursos materiales, tecnológicos y humanos en los juzgados, que requerirá un aumento presupuestal para contratar y cubrir las plazas de juezas, jueces, personal jurisdiccional y administrativo necesario para afrontar la carga procesal en materia de alimentos. Asimismo, para la adquisición o alquiler de bienes inmuebles donde se ubiquen estos juzgados de acuerdo a la cobertura población/juez, y de los bienes muebles, tales como mesas, sillas, computadoras, material de oficina, acceso a internet, entre otros, que permitan la mejora de los servicios que brindan los juzgados existentes y que carecen de estos bienes y, también, de los que se deben implementar.

Además, se debe resaltar que, el Consejo Ejecutivo del Poder Judicial aprobó el proceso simplificado y virtual de pensión de alimentos para la niña, niño y adolescente, en junio de 2020, por lo que estamos seguros de que será un instrumento trascendental en la reducción de la carga al aplicar la celeridad y la economía procesal.

Por otro lado, se preguntó a los magistrados si ¿reciben capacitación sobre el derecho de alimentos? La mayoría contestó que no (67\%), debido a que el Poder Judicial los capacita, regularmente, en otras materias, y que, en la Academia de la Magistratura, los cupos son limitados, principalmente dirigidos a juezas y jueces 
titulares, y son uno o dos los cursos que se desarrollan en el año, por lo que deben buscar otras alternativas de capacitación, como en las universidades.

\section{CONCLUSIONES}

Mediante la gestión de política pública se logrará cumplir oportunamente los procesos de pensión de alimentos en los juzgados de paz letrados, como quedo comprobado en el trabajo de campo (encuesta) realizado a las juezas y jueces del distrito judicial de Lima Norte, que vienen implementando un sistema de gestión de calidad en atención a estos procesos judiciales.

La mayoría de las juezas y jueces consideran que la población, especialmente aquella en condición de vulnerabilidad, no cuenta con información accesible y completa sobre el proceso de pensión de alimentos, lo que limita el pleno ejercicio de sus derechos humanos.

Quedó demostrado que los juzgados de paz letrado que no tratan con celeridad los procesos de pensión de alimentos perjudican y vulneran los derechos fundamentales de la parte demandante.

La mayoría de procesos de pensión de alimentos involucran a menores de edad, y al no ser tramitados con celeridad se vulneran sus derechos humanos, tales como: la alimentación, la salud, la vestimenta, la recreación, la educación, entre otros que son fundamentales para su desarrollo integral.

La mayoría de los juzgados de paz letrado tienen una gran carga procesal en materia de pensión de alimentos, que impide que éstos se resuelvan con celeridad y dentro del plazo legal, sumado a otras causas, tales como el problema de la notificación, la programación de la audiencia y la ejecución efectiva de la sentencia.

Es insuficiente la cantidad de juezas y jueces de paz letrado para conocer los procesos de pensión de alimentos en el distrito judicial al que pertenecen, debido a que no está distribuida de forma uniforme el trinomio de población/expedientes/magistrados.

Existe un sistema de gestión de procesos para la celeridad de las demandas de pensión de alimentos, establecido en los objetivos del Plan Nacional de Acceso a la Justicia de Personas en Condición de Vulnerabilidad 2016-2021, pero que no se cumple, debido a diversos factores relacionados a la insuficiencia de recursos económicos, tecnológicos, materiales y humanos.

\section{REFERENCIAS BIBLIOGRÁFICAS}

Aparicio, I. (2018). Análisis práctico de la pensión alimenticia de los hijos en el actual Código Civil español: posibles soluciones para los pleitos de familia. Tesis para optar el grado de Doctor en Derecho por la Universidad Complutense de Madrid, España. Recuperado de: https://n9.cl/xab3|

Beloff, M. (2001). Los sistemas de responsabilidad penal juvenil en América Latina. En González Oviedo, M. y Vargas Ulate, E. (comps.). Derechos de la Niñez y la Adolescencia. Antología (pp.301-321). Recuperado de: https://n9.cl/t9nni

Berríos, B. (2018). La unificación de los procesos de familia en el Perú. Tesis para optar por el título profesional de abogado por la Universidad Católica Santo Toribio de Mogrovejo. Recuperado de: https://n9.cl/ts8er

Boneti, L. (2017). Políticas públicas por dentro. Buenos Aires, Argentina. CLACSO. Recuperado de: https://n9.cl/510in

Comisión de Justicia de Género del Poder Judicial (2018). Número de jueces y juezas a nivel nacional. Recuperado de: https://n9.cl/fr1lx

Consejo Ejecutivo del Poder Judicial. (2016). Plan Nacional de Acceso a la Justicia de Personas en Condición de Vulnerabilidad - Poder Judicial del Perú 2016-2021. Resolución Administrativa N090-2016-CE-PJ. Recuperado de: https://n9.cl/o8c0u

Cumbre Judicial Iberoamericana. (2008). Reglas de Brasilia de Acceso a la Justicia sobre Personas en Condición de Vulnerabilidad. Recuperado de: https://n9.cl/gjll 
Cumbre Judicial Iberoamericana. (2018). Reglas de Brasilia de Acceso a la Justicia sobre Personas en Condición de Vulnerabilidad. Recuperado de: https://n9.cl/uzqf6

Defensoría del Pueblo. (2018). El proceso de alimentos en el Perú: avances, dificultades y retos. Informe $N^{\circ}$ 001-2018-DP/AAC. Lima, Perú: Defensoría del Pueblo. Recuperado de: https://n9.cl/oocmx

Elver, H. (2019). Defender el derecho de un niño a los alimentos y la nutrición. En Estado Mundial de la Infancia 2019: Niños, alimentos y nutrición (pp. 32-33). UNICEF. Recuperado de: https://n9.cl/8z33

Fernández, W. (2020). Gestión de política pública para la celeridad en los procesos de pensión de alimentos en los Juzgados de Paz Letrado de la Corte Superior de Justicia de Lima Norte en el período 2018-2019. Memoria para optar el Grado Académico en Gestión Pública por el Instituto de Gobierno y Gestión Pública de la Universidad de San Martín de Porres. Recuperado de: https://n9.cl/rm3e1

García-Méndez, E. (2004). Legislaciones infanto-juveniles en América Latina: modelos y tendencias. Infancia. De los derechos y de la justicia (pp.1-16). Buenos Aires, Argentina: Editores del Puerto.

García-Méndez, E. (2001). Legislaciones infanto-juveniles en América Latina: modelos y tendencias. En González Oviedo, M. y Vargas Ulate, E. (comps.). Derechos de la Niñez y la Adolescencia. Antología (pp.59-72). Recuperado de: https://n9.cl/t9nni

Garro, A. (1999). El acceso a la justicia y el "derecho de interés público". En la Revista Justicia y Sociedad, (2). PNUD.

Gómez, H. (2013). Desafíos para garantizar el derecho a la alimentación: las experiencias contrastantes de México y Brasil. México D.F., México: CEPAL. Recuperado de: https://n9.cl/07jru

Jarama, Z., Vásquez, J. y Durán, A. (2019, enero). El principio de celeridad en el código orgánico general de procesos, consecuencias en la audiencia. En Universidad y Sociedad, 11 (1), pp.314-323. Recuperado de: https://n9.cl/o8nil

Lahera, E. (2006). Encuentros y desencuentros entre política y políticas públicas. En Franco, R. y Lanzaro, J. (coords.) Política y políticas públicas en los procesos de reforma de América Latina, pp.75-100. Buenos Aires, Argentina: CEPAL. Recuperado de: https://n9.cl/8hof0

Lahera, E. (2004). Política y políticas públicas. Santiago de Chile, Chile: CEPAL. Recuperado de: https://n9.cl/k3fmv

Landa, C. (2017). Los derechos fundamentales. Lima, Perú: Fondo Editorial de la Pontificia Universidad Católica del Perú.

La Rosa, J. (2009) El acceso a la justicia como condición para una reforma judicial en serio. En la Revista de la Facultad de Derecho PUCP, (62), pp.115-128. Recuperado de: https://n9.cl/cx8h

Ministerio de Justicia y Derechos Humanos. (2016). Acuerdo Nacional por la Justicia. Recuperado de: https://n9.cl/f7kyv

Ministerio de la Mujer y Poblaciones Vulnerables. (2012). Plan Nacional de Acción por la Infancia y la Adolescencia 2012-2021. Decreto Supremo №01-2012-MIMP. Recuperado de: https://n9.cl/c811e

Naciones Unidas. (2015). Agenda 2030 para el Desarrollo Sostenible. Recuperado de: https://n9.cl/ecj1

Navarro, Y. (2014). Incumplimiento del deber alimentario hacia niños, niñas y adolescentes. Tesis para optar el grado académico de magister en Política Social con mención en Promoción de la Infancia por la Universidad Nacional Mayor de San Marcos. Recuperado de: https://n9.cl/6bt1d

O'Donnell, D. (2001). La Convención sobre los Derechos del Niño: estructura y contenido. En González Oviedo, M. y Vargas Ulate, E. (comps.). Derechos de la Niñez y la Adolescencia. Antología (pp.15-30). Recuperado de: https://n9.cl/t9nni

Poder Judicial del Perú. (2019, diciembre). Boletín estadístico institucional N04-2019. Recuperado de: https://n9.cl/vtuk

Poder Judicial del Perú. (2019). Plan de gestión y desarrollo del Poder Judicial. Periodo 2019-2020. 
Poder Judicial del Perú. (2018, diciembre). Boletín estadístico institucional N04-2018. Recuperado de: https://n9.cl/wkuvi

Poder Judicial del Perú. (2010). Tercer Pleno Casatorio, recaído en la Casación N46642010-Puno.

Presidencia del Consejo de Ministros del Gobierno del Perú. (2017). Política Nacional de Modernización de la Gestión Pública al 2021.

Priori, G. (2019). El proceso y la tutela de los derechos. Lima, Perú: Fondo Editorial de la Pontificia Universidad Católica del Perú.

Velásquez, R. (2009). Hacia una nueva definición del concepto "política pública". En la Revista Desafíos, 20, pp.149-187. Recuperado de: https://n9.cl/sreh3 